\title{
Effect of condensed tannins on bovine rumen protist diversity based on 18S rRNA gene sequences
}

\begin{abstract}
Molecular diversity of protists from bovine rumen fluid incubated with condensed tannins of Leucaena leucocephala hybrid-Rendang at $20 \mathrm{mg} / 500 \mathrm{mg}$ dry matter (treatment) or without condensed tannins (control) was investigated using 18S rRNA gene library. Clones from the control library were distributed within nine genera, but clones from the condensed tannin treatment clone library were related to only six genera. Diversity estimators such as abundance-based coverage estimation and Chao 1 showed significant differences between the two libraries, although no differences were found based on Shannonï Weaver index and Libshuff.
\end{abstract}

Keyword: Bovine rumen fluid; Molecular diversity; Protist 